\title{
ERKs and mitochondria-related pathways are essential for glycyrrhizic acid-mediated neuroprotection against glutamate-induced toxicity in differentiated PC12 cells
}

\author{
D. Wang ${ }^{1,2}$, T.Q. Guo ${ }^{1}$, Z.Y. Wang ${ }^{3}$, J.H. Lu ${ }^{1}$, D.P. Liu ${ }^{1}$, Q.F. Meng ${ }^{1}$, J. Xie ${ }^{1}$, X.L. Zhang ${ }^{4}$, \\ Y. Liu ${ }^{1}$ and L.S. Teng ${ }^{1,2}$ \\ ${ }^{1}$ School of Life Sciences, Jilin University, Changchun, China \\ ${ }^{2}$ The State Engineering Laboratory of AIDS Vaccine, Jilin University, Changchun, China \\ ${ }^{3}$ State Key Laboratory of Theoretical and Computational Chemistry, Jilin University, Changchun, China \\ ${ }^{4}$ Faculty of Science, National University of Singapore, Singapore
}

\begin{abstract}
The present study focuses on the neuroprotective effect of glycyrrhizic acid (GA, a major compound separated from Glycyrrhiza Radix, which is a crude Chinese traditional drug) against glutamate-induced cytotoxicity in differentiated PC12 (DPC12) cells. The results showed that GA treatment improved cell viability and ameliorated abnormal glutamate-induced alterations in mitochondria in DPC12 cells. GA reversed glutamate-suppressed B-cell lymphoma 2 levels, inhibited glutamateenhanced expressions of Bax and cleaved caspase 3, and reduced cytochrome C (Cyto C) release. Exposure to glutamate strongly inhibited phosphorylation of AKT (protein kinase B) and extracellular signal-regulated kinases (ERKs); however, GA pretreatment enhanced activation of ERKs but not AKT. The presence of PD98059 (a mitogen-activated protein/extracellular signal-regulated kinase kinase [MEK] inhibitor) but not LY294002 (a phosphoinositide 3-kinase [PI3K] inhibitor) diminished the potency of GA for improving viability of glutamate-exposed DPC12 cells. These results indicated that ERKs and mitochondriarelated pathways are essential for the neuroprotective effect of GA against glutamate-induced toxicity in DPC12 cells. The present study provides experimental evidence supporting GA as a potential therapeutic agent for use in the treatment of neurodegenerative diseases.
\end{abstract}

Key words: Glycyrrhizic acid; Neuroprotection; Glutamate; ERKs; Mitochondria

\section{Introduction}

The excitatory amino acid glutamate serves as a fast excitatory neurotransmitter in the central nervous system (1), and excitotoxicity and oxidative toxicity are considered to be two major pathways responsible for glutamateinduced toxicity $(2,3)$. Excessive release of glutamate leading to excitotoxicity is responsible for neuronal injury associated with many acute and chronic brain diseases, such as brain ischemia, traumatic brain injury, and neurodegenerative disorders $(4,5)$.

Glycyrrhiza Radix, a crude Chinese traditional drug derived from Glycyrrhiza uralensis, G. glabra and G. inflata, exhibits various pharmacological activities including anti-inflammatory (6), anti-obesity (7), anti-virus (8), and anti-oxidative (9) effects. Glycyrrhizic acid (GA), a major component of Glycyrrhiza Radix, possesses antiinflammatory and anti-viral effects $(10,11)$. Its structure is shown in Figure 1A. A previous study demonstrated that GA exerts a neuroprotective effect against 6-hydroxydopamine-induced PC12 cell death via the phosphoinositide 3-kinase $(\mathrm{PI} 3 \mathrm{~K}) /$ protein kinase $B(\mathrm{AKT})$ pathway (12). The protective effect of GA was also confirmed in rat primary neurons and hippocampal slices (13). However, the protective effects of GA against glutamate-induced differentiated PC12 (DPC12) cell damage and the underlying mechanisms have not been described.

Several signaling pathways are involved in the regulation of glutamate-induced neurotoxicity $(14,15)$. Alteration of mitochondrial function is one of the factors 

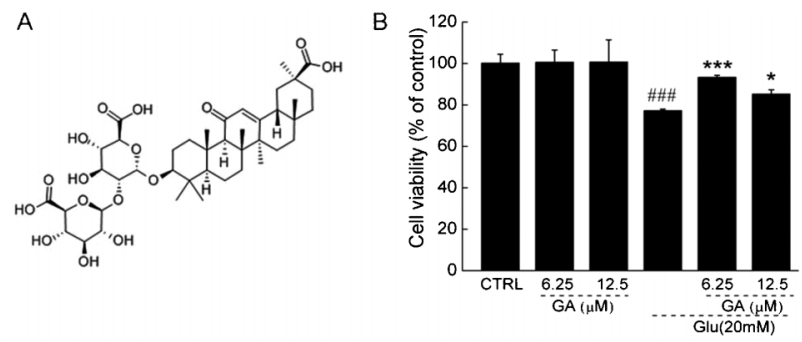

Figure 1. $A$, Chemical structure of glycyrrhizic acid (GA). $B, \mathrm{GA}$ enhanced cell viability in differentiated PC12 cells exposed to glutamate (Glu). Differentiated PC12 cells were pre-treated with $\mathrm{GA}$ for $3 \mathrm{~h}$ and then co-treated with or without Glu for another $24 \mathrm{~h}$. Data are reported as a percentage (means $\pm S D$ ) of that from corresponding control cells $(C T R L)(n=3)$. ${ }^{\# \# \# P<0.001 ~ v s ~}$ CTRL; ${ }^{*} \mathrm{P}<0.05$ and ${ }^{* * *} \mathrm{P}<0.001$ vs Glu-treated cells (one-way ANOVA followed by Dunn's test).

responsible for cell damage (16). Bax and B-cell lymphoma 2 (Bcl-2), located in mitochondria, are believed to be central regulators of mitochondrial function (17). Additionally, activation of both AKT and extracellular signal-regulated kinases (ERKs) is considered to contribute to cell proliferation and apoptosis $(18,19)$. Previous studies demonstrated that inhibition of phosphorylation of both AKT and ERKs is involved in glutamate-induced cell damage $(20,21)$.

Our study aimed to examine the effect of GA on attenuating glutamate cytotoxicity and its underlying mechanisms in DPC12 cells. Our results showed that GA improved cell viability and restored mitochondrial membrane potential dissipation. GA also normalized the expression of apoptosis-related proteins, including Bcl-2, Bax, cleaved caspase 3, and cytochrome C (Cyto C). Furthermore, GA pretreatment remarkably enhanced phosphorylation of ERKs but not AKT. Collectively, our findings demonstrated that ERKs and mitochondriarelated pathways are essential for GA-mediated neuroprotection against glutamate-induced toxicity in DPC12 cells. This study provides evidence that supports the use of GA as a potential therapeutic agent for neurodegenerative diseases.

\section{Material and Methods}

\section{Cell culture}

PC12 cells (CRL-1721, passages $<10$; obtained from ATCC) were grown in monolayers in collagen l-coated flasks with Dulbecco's modified Eagle's medium (Invitrogen, USA) supplemented with 10\% horse serum (HS, Invitrogen), 5\% fetal bovine serum (FBS, Invitrogen), penicillin $(100 \mathrm{U} / \mathrm{mL})$, and streptomycin $(100 \mu \mathrm{g} / \mathrm{mL}$, Invitrogen), under a humidified atmosphere containing $5 \% \mathrm{CO}_{2}$ and $95 \%$ air at $37^{\circ} \mathrm{C}$. The culture medium was changed every 3 days. PC12 cells were differentiated with $20 \mathrm{ng} / \mathrm{mL}$ nerve growth factor for $48 \mathrm{~h}$, which was added to the culture medium containing $1 \%$ FBS and $1 \% \mathrm{HS}$.
Cells were ready for treatment when they reached $80 \%$ confluence.

\section{Cell viability analysis}

Cell viability was measured by a quantitative colorimetric assay with 3-(4,5-cimethylthiazol-2-yl)-2,5-diphenyl tetrazolium bromide (MTT; Sigma-Aldrich, USA) as reported previously (22). Briefly, PC12 cells were seeded onto 96 -well plates at $1 \times 10^{4}$ cells/well. After differentiation, cells were pretreated with $6.25-12.5 \mu \mathrm{M}$ GA for $3 \mathrm{~h}$ and exposed to $20 \mathrm{mM}$ glutamate for $24 \mathrm{~h}$. In separate experiments, cells were pretreated with $10 \mu \mathrm{M}$ LY294002 (PI3K inhibitor) or $10 \mu \mathrm{M}$ PD98059 [a mitogen-activated protein/extracellular signal-regulated kinase kinase (MEK) inhibitor] for $30 \mathrm{~min}$, followed by treatment with 6.25 $12.5 \mu \mathrm{M}$ GA for $3 \mathrm{~h}$ and exposure to $20 \mathrm{mM}$ glutamate for $24 \mathrm{~h}$. Treated cells were incubated with MTT solution $(0.5 \mathrm{mg} / \mathrm{mL})$ for $4 \mathrm{~h}$ at $37^{\circ} \mathrm{C}$ in the dark. One hundred microliters of dimethyl sulfoxide were used to dissolve crystals. Absorbance was measured spectrophotometrically using a microplate reader (Bio-Rad, USA) at $540 \mathrm{~nm}$. The viability of treated cells are reported as a percentage of that from corresponding control cells.

\section{Mitochondrial membrane potential (MMP) analysis}

5,5',6,6'-Tetrachloro-1,1',3,3' tetraethylbenzimidazolylcarbocyanine iodide (JC-1, Sigma-Aldrich) staining was used to measure MMP changes. PC12 cells were seeded onto six-well plates at $1 \times 10^{5}$ cells/well. After differentiation, cells were pretreated with 6.25 or $12.5 \mu \mathrm{M}$ GA for $3 \mathrm{~h}$ and cotreated with glutamate for another $12 \mathrm{~h}$. Next, cells were incubated with $2 \mu \mathrm{M} \mathrm{JC}-1$ at $37^{\circ} \mathrm{C}$ for $10 \mathrm{~min}$. After three washes with phosphate-buffered saline, fluorescent color in each group was examined using a fluorescence microscope (20×; Axio Observer Z1, CCD camera; Carl Zeiss, Germany). Red fluorescence indicated healthy cells with high MMP, whereas green fluorescence indicated apoptotic or unhealthy cells with low MMP. The average ratio of the red $(590 \mathrm{~nm})$ to green $(540 \mathrm{~nm})$ fluorescence intensity of each cell in the different groups was calculated using the ImageJ software (National Institutes of Health, USA). A total of 50 cells were calculated in each group. The values of treated cells are reported as a percentage of that from corresponding control cells.

\section{Western blotting}

Treated cells were lysed using radioimmunoprecipitation assay buffer (Sigma-Aldrich, USA) containing 1\% protease inhibitor cocktail and $2 \%$ phenylmethanesulfonyl fluoride. Detection of Cyto $\mathrm{C}$ release from mitochondria to cytoplasm was performed using cytoplasmic extracts prepared as described previously (23). The supernatants were collected, and protein concentrations were determined by the Bradford method. Proteins were separated using $12 \%$ sodium dodecyl sulfate-polyacrylamide gel electrophoresis and transferred electrophoretically onto 
nitrocellulose membranes (Bio Basic, USA). The transferred membranes were then blotted with antibodies as follows: phospho-ERKs (P-ERKs), total-ERKs (T-ERKs), phosphor-AKT (P-AKT), total-AKT (T-AKT), Bcl-2, Bax, cleaved caspase 3, Cyto C, and glyceraldehyde-3phosphate dehydrogenase (all 1:1,000; Cell Signaling, USA) at $4^{\circ} \mathrm{C}$ overnight, followed by treatment with horseradish peroxidase-conjugated secondary antibodies (Santa Cruz Biotechnology, USA). The signals were detected with enhanced chemiluminescence detection kits (GE Healthcare, UK). The intensities of the bands were quantified with scanning densitometry using the Quantity One 4.5.0 software (Bio-Rad).

\section{Statistical analysis}

One-way analysis of variance followed by post hoc multiple comparisons (Dunn's test) were performed to detect statistically significant differences $(P<0.05)$. Data are reported as means $\pm S D$.

\section{Results}

\section{Effect of GA against glutamate-induced cell damage in DPC12 cells}

GA alone did not affect DPC12 cell proliferation. Exposure to $20 \mathrm{mM}$ glutamate for $24 \mathrm{~h}$ resulted in decreased viability of $77.3 \pm 0.6 \%$; however, pretreatment with 6.25 and $12.5 \mu \mathrm{M}$ GA significantly prevented the loss of cell viability, enhancing viability to $93.4 \pm 0.9 \%$ $(P<0.001)$ and $85.3 \pm 1.9 \% \quad(P<0.05)$, respectively (Figure 1B).

\section{GA restored glutamate-induced MMP dissipation}

JC-1 staining was used to examine MMP changes in treated cells. GA strongly restored glutamate-induced MMP dissipation, as demonstrated by an increment in red fluorescence emission compared with glutamate-treated cells (Figure 2). As shown in the quantification data, compared to the control group, only $21.2 \pm 8.7 \%$ $(\mathrm{P}<0.001)$ MMP was observed in glutamate-treated cells. Conversely, 6.25 and $12.5 \mu \mathrm{M}$ GA pretreatment significantly restored MMP to $69.9 \pm 12.9 \% \quad(P<0.01)$ and $36.1 \pm 6.9 \%(P<0.05)$, respectively (Figure 2$)$.

\section{Effects of GA on expression of Bcl-2, Bax, cleaved caspase 3, and Cyto C}

Compared to control cells, Bcl-2, Bax, cleaved caspase 3, and Cyto $C$ (cytoplasm) expression levels were $75.9 \pm 4.3 \% \quad(P<0.05), 124.3 \pm 8.8 \% \quad(P<0.05)$, $155.5 \pm 10.6 \%(P<0.01)$, and $119.8 \pm 3.2 \%(P<0.05)$ in cells exposed to $20 \mathrm{mM}$ glutamate for $24 \mathrm{~h}$ (Figure 3). GA pretreatment $(6.25$ or $12.5 \mu \mathrm{M})$ strongly restored glutamate-reduced Bcl-2 levels to $102.3 \pm 12.7$ or $95.1 \pm 10.9 \%$ $(\mathrm{P}<0.05)$, normalized glutamate-increased Bax expression to $78.7 \pm 4.4$ or $80.3 \pm 6.4 \% \quad(P<0.01)$, inhibited caspase 3 activity to $119.4 \pm 10.1 \%$ or $112.3 \pm 10.9 \%$
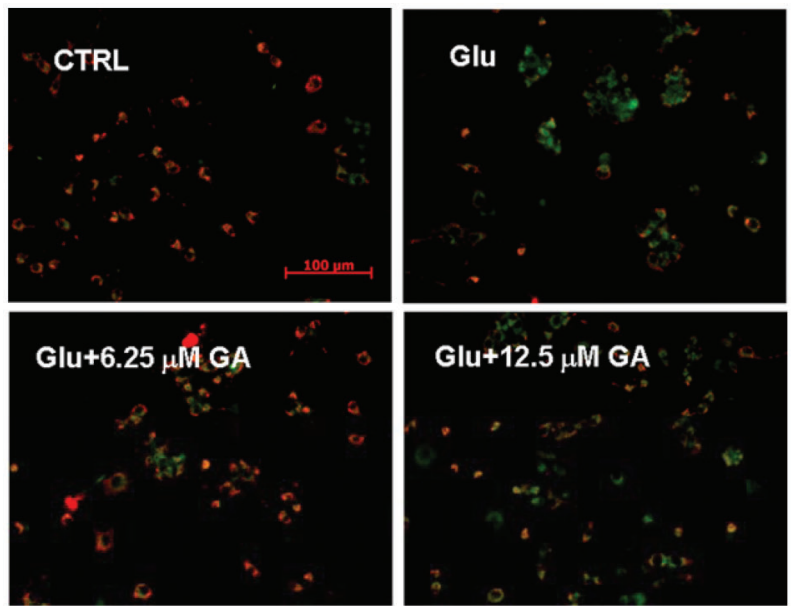

궁

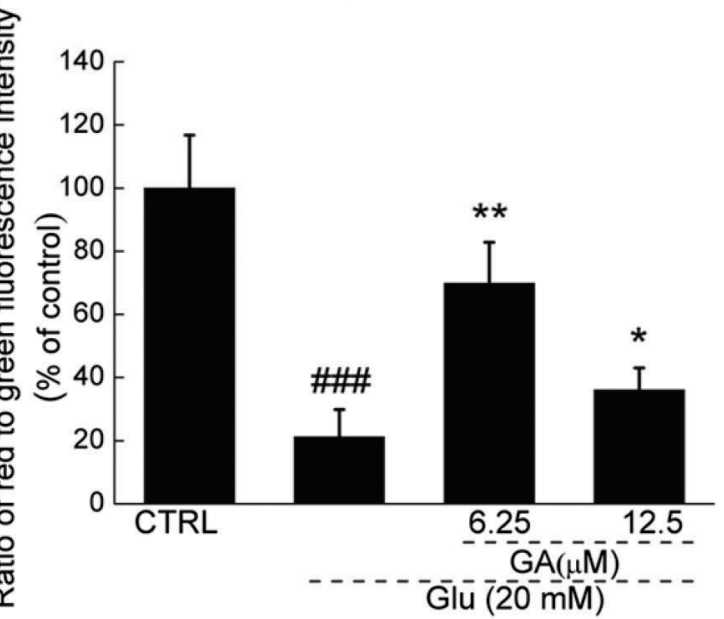

Figure 2. Glycyrrhizic acid (GA) restored glutamate-disturbed mitochondrial function $(20 \times$; Scale bar: $100 \mu \mathrm{m})$. Differentiated PC12 cells were pretreated with 6.25 and $12.5 \mu \mathrm{M}$ GA for $3 \mathrm{~h}$ and exposed to $20 \mathrm{mM}$ glutamate (Glu) for $12 \mathrm{~h}$. The changes of mitochondrial membrane potential (MMP) were determined by JC-1 staining. Red fluorescence indicates healthy cells with high MMP, whereas green fluorescence indicates apoptotic or unhealthy cells with low MMP. Average ratio of red $(590 \mathrm{~nm})$ to green $(540 \mathrm{~nm})$ fluorescent intensity of each cell in different groups was calculated $(n=50)$ and data are reported as a percentage (means $\pm S D$ ) of that from corresponding control cells (CTRL). \#\#\# $\mathrm{P}<0.001$ vs CTRL; ${ }^{*} \mathrm{P}<0.05$ and ${ }^{* *} \mathrm{P}<0.01$ vs Glu-treated cells (one-way ANOVA followed by Dunn's test).

$(\mathrm{P}<0.05)$, and suppressed Cyto $\mathrm{C}$ release to $102.2 \pm 7.9$ or $98.9 \pm 6.8 \%(P<0.05)$, respectively (Figure 3$)$.

\section{Activation of ERKs but not AKT contributes to GA-mediated neuroprotective effect}

Glutamate significantly suppressed $\mathrm{P}$-ERK levels from 30 to $360 \mathrm{~min}$ (from $71.1 \pm 11.3$ to $85.7 \pm 8.2 \%$; $\mathrm{P}<0.05$ ) but did not affect T-ERK levels. Conversely, GA alone increased P-ERK expression at 180 and $360 \mathrm{~min}$ $(132.2 \pm 7.2$ and $132.3 \pm 12.2 \%$, respectively; $\mathrm{P}<0.05$; 
Figure 4A). GA pretreatment $(6.25 \mu \mathrm{M})$ reversed the decrease in P-ERKs caused by glutamate, with a significant effect observed at 180 and $360 \mathrm{~min}$ $(116.2 \pm 4.1$ and $121.3 \pm 3.5 \%$, respectively; $\mathrm{P}<0.05$; Figure 4A). Further results showed that after pretreatment with $10 \mu \mathrm{M}$ PD98059 for $30 \mathrm{~min}$ followed by a 3-h treatment of GA and exposure to glutamate for another $24 \mathrm{~h}$, the neuroprotective effect of $6.25 \mu \mathrm{M}$ GA on cell viability was significantly abrogated $(80.7 \pm 4.5$ vs $71.7 \pm 5.7 \%$; $P<0.05$; Figure $4 C$ ). Collectively our results indicate that ERK activation was involved in GA-mediated neuroprotection in DPC12 cells.

Glutamate time-dependently reduced P-AKT levels from 30 to $360 \min (12.1 \pm 2.2 \%$ to $19.6 \pm 8.9 \%$ reduced, respectively; $\mathrm{P}<0.05)$. However, neither $\mathrm{GA}$ alone nor cotreatment with glutamate showed any effect on P-AKT levels (Figure 4B). Furthermore, the effect GA on cell
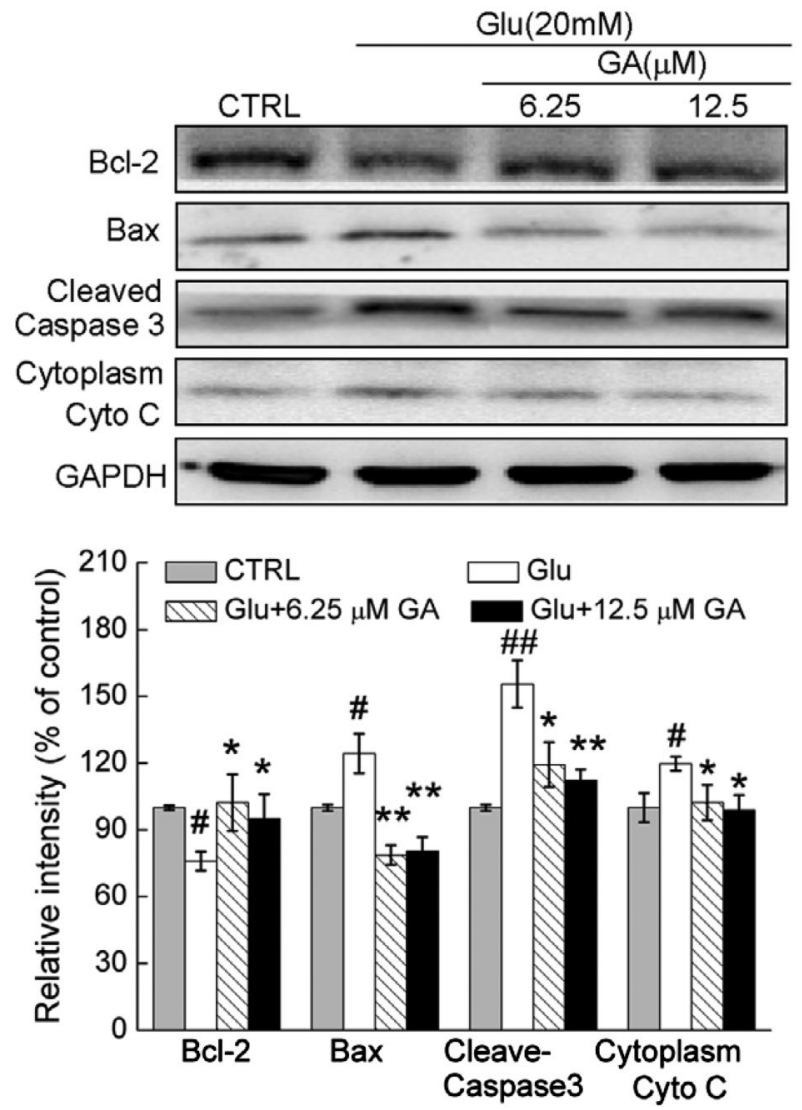

Figure 3. Glycyrrhizic acid (GA) restored the apoptotic alterations of apoptosis related proteins (Bcl-2, Bax, cleaved caspase 3 and cytoplasm Cyto C) caused by glutamate (Glu). Differentiated PC12 cells were pre-treated with GA for $3 \mathrm{~h}$ and then co-treated with Glu for another $24 \mathrm{~h}$. Quantification data were normalized by GAPDH. Data are reported as a percentage (means $\pm S D$ ) of that from corresponding control cells $(C T R L)(n=3)$. ${ }^{\#} P<0.05$, and \#\# $\mathrm{P}<0.01$ vs CTRL; ${ }^{*} \mathrm{P}<0.05$ and ${ }^{* *} \mathrm{P}<0.01$ vs Glu-treated cells (one-way ANOVA followed by Dunn's test). viability was not altered by a 30-min pretreatment with $10 \mu \mathrm{M}$ LY290002 (a specific PI3K inhibitor) (Figure 4D). These data indicate that the AKT pathway is not involved in this neuroprotective effect.

\section{Discussion}

As a major compound of Glycyrrhiza Radix, GA has been studied for years. GA is neuroprotective in the postischemic brain mainly through anti-excitotoxic and anti-oxidative effects (24). GA protects against 3-morpholinosydnonimine-induced cell damage in lung epithelial cells (25). Recently, it was reported that GA inhibits extracellular high-mobility group box 1 cytokine activity and reduces the level of the inflammatory response, thus alleviating early brain injury and cerebrovasospasm (26). Our present study revealed that GA improved cell viability, restored mitochondrial dysfunction, and normalized expression of Bax, Bcl-2, cleaved caspase 3, and Cyto C compared with cells exposed to glutamate. GA enhanced P-ERK but not P-AKT levels. Further experiments employing MEK and PI3K inhibitors demonstrated that the ERK signaling pathway is essential in GAmediated neuroprotection.

ERK and AKT activations are major factors related to cell survival $(14,15)$. Activated ERKs and stress-activated c-Jun N-terminal kinase-P38 have important roles in PC12 survival (27). Another study reported that sodium ferulate exerts neuroprotective effects against glutamateinduced apoptosis via ERK and AKT pathways (21). In the present study, both GA treatment alone and cotreatment with glutamate induced ERK phosphorylation, whereas glutamate downregulated P-ERK levels. However, neither GA treatment alone nor cotreatment with glutamate affected AKT activation. The presence of PD98059 but not LY294002 partially abrogated the protective effect on cell viability and further confirmed the role of ERKs in GAmediated neuroprotection against glutamate-induced cytotoxicity in DPC12 cells.

On the other hand, growing experimental evidence indicates that mitochondrial function plays a central role in cell apoptosis (28). Results revealed that GA restored mitochondrial dysfunction, suppressed expression of Bax and cleaved caspase 3 , enhanced expression of $\mathrm{Bcl}-2$, and inhibited Cyto $\mathrm{C}$ release compared to glutamatetreated cells. Bcl-2 family members play crucial roles in regulating cell death, and the ratio $\mathrm{Bcl}-2 / \mathrm{Bax}$ is considered a hallmark for determining the relationship between cell death and mitochondrial dysfunction (29). It is believed that when MMP dissipation is observed, release of Cyto $C$ from the mitochondria to the cytoplasm is enhanced. Caspases are a family of cysteine proteases that play pivotal roles in mediating neuronal apoptosis and neurodegeneration (30). As a critical apoptosis executioner, caspase 3 becomes activated in the cytosol and is translocated into the nucleus to cleave its nuclear 

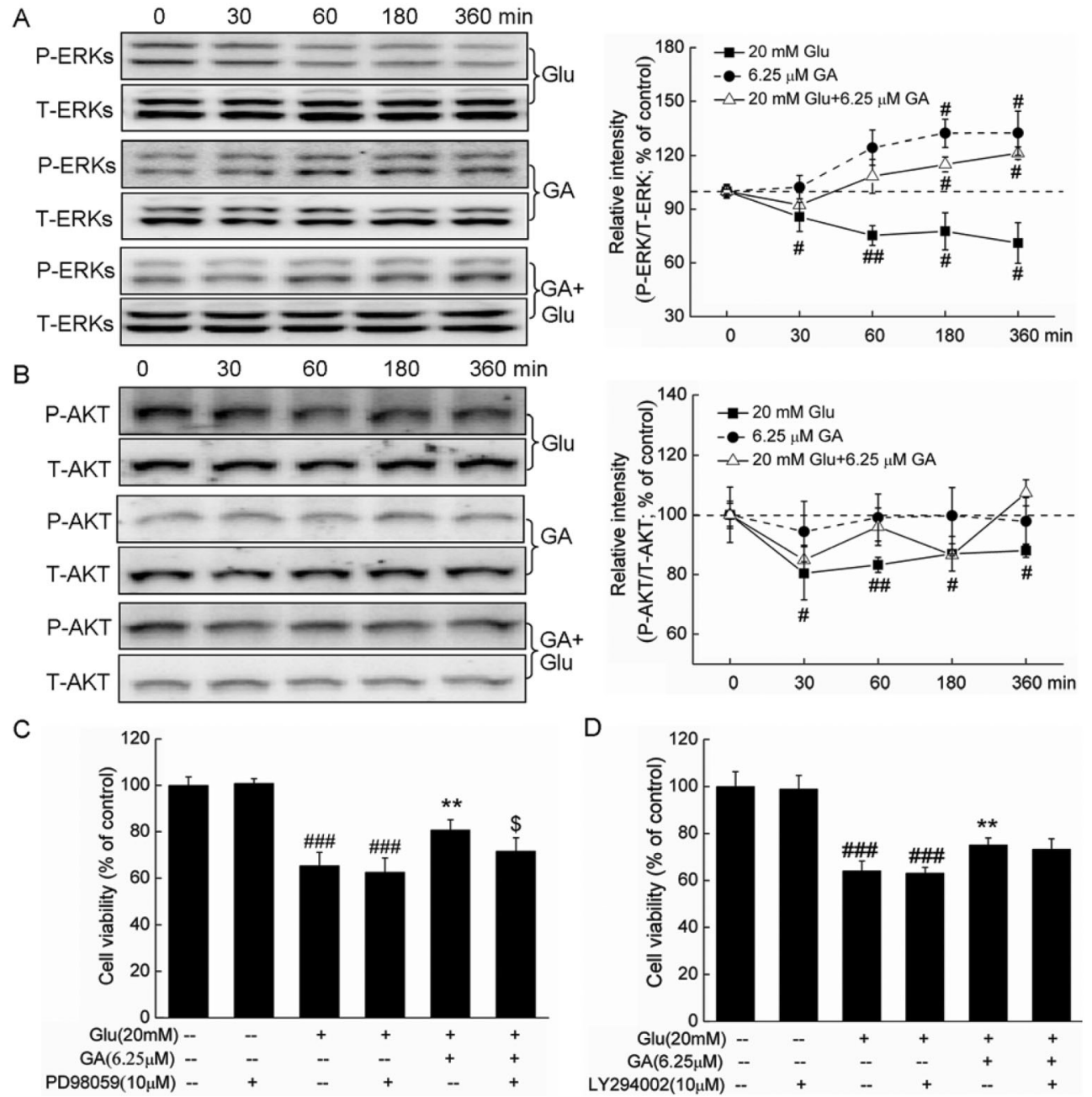

Figure 4. ERKs but not the AKT pathway were involved in the glycyrrhizic acid (GA)-mediated neuroprotective effect against glutamate-induced differentiated PC12 cell damage. A, B, Differentiated PC12 cells were treated with $6.25 \mu \mathrm{M}$ GA or 20 mM glutamate (Glu) alone and collected at 0, 30,60, 180, and $360 \mathrm{~min}$. In co-treatment, following pretreatment with $6.25 \mu \mathrm{M} \mathrm{GA}$ for $3 \mathrm{~h}$, cells were collected at $0,30,60,180$, and 360 min after Glu exposure. The expressions of P-ERKs, T-ERKs, P-AKT, T-AKT were detected by Western blot. Quantification data were normalized by related T-ERKs and T-AKT, respectively. C, D, Protective effects of GA against Glu on cell viability were abolished significantly by PD98059 but not by LY294002 pretreatment. Differentiated PC12 cells were pretreated with $10 \mu \mathrm{M}$ PD98059 or LY294002 for $30 \mathrm{~min}$, followed by treatment with $6.25 \mu \mathrm{M}$ GA for $3 \mathrm{~h}$ and exposure to $20 \mathrm{mM}$ Glu for $24 \mathrm{~h}$. Cells were then collected for measurement of cell viability using the MTT method. ERKs: extracellular signal-regulated kinases; AKT: protein kinase B; P-ERKs: phospho-ERKs; T-ERKs: total-ERKs; P-AKT: phosphor-AKT; T-AKT: total-AKT. Data are reported as a percentage (mean $\pm S D$ ) of that from corresponding control cells $(n=3)$. ${ }^{\#} P<0.05,{ }^{\#} P<0.01$, \#\#\# $P<0.001$ vs control cells; ${ }^{* *} \mathrm{P}<0.01$ vs Glu-treated cells; ${ }^{\$} \mathrm{P}<0.05$ vs $\mathrm{GA}$ and Glu co-treated cells (one-way ANOVA followed by Dunn's test).

substrates (31). Disruption of MMP unleashes the enzymatic apoptotic machinery of caspases, and of caspase 3 in particular, which executes apoptosis. Thus, it is not surprising that mitochondria-related pathways are involved in GA-mediated neuroprotection. Additionally, as reported, inhibition of ERK leads to downregulation of Bcl2 and $\mathrm{BCl}-\mathrm{xL}$ expression (32). However, the relationship between ERK activation and mitochondrial function needs further study.

Although doses ranging from 1 to $50 \mu \mathrm{M}$ GA were employed in the preliminary experiment, protective effects against glutamate-caused cell damage were only noted at 6.25 and $12.5 \mu \mathrm{M}$. The data suggested that $6.25 \mu \mathrm{M}$ GA had a more potent effect. Interestingly, recent research reported that GA exerts an apoptotic effect in WEHI-3 mouse leukemia cells (33) and against $\mathrm{DMH}$-induced colon carcinogenesis in Wistar rats (34). It appears that GA possesses biphasic properties, that is, GA shows protective activities in neurodegenerative diseases and neural injury, whereas it has apoptotic effects in cancer. 
The biphasic properties may also be related to the dosages employed. Detailed mechanisms underlying such biphasic effects deserve further study.

In conclusion, GA protects DPC12 cells against glutamate-induced neurotoxicity mainly through ERK and mitochondria-related pathways. Our findings provide experimental evidence that GA may be a candidate for treating or preventing neurodegenerative diseases.

\section{References}

1. Traynelis SF, Wollmuth LP, McBain CJ, Menniti FS, Vance $\mathrm{KM}$, Ogden KK, et al. Glutamate receptor ion channels: structure, regulation, and function. Pharmacol Rev 2010; 62: 405-496, doi: 10.1124/pr.109.002451.

2. Reynolds IJ, Hastings TG. Glutamate induces the production of reactive oxygen species in cultured forebrain neurons following NMDA receptor activation. J Neurosci 1995; 15: 3318-3327.

3. Akaishi $\mathrm{T}$, Nakazawa $\mathrm{K}$, Sato $\mathrm{K}$, Saito $\mathrm{H}$, Ohno $\mathrm{Y}$, Ito $\mathrm{Y}$. Hydrogen peroxide modulates whole cell $\mathrm{Ca}^{2+}$ currents through L-type channels in cultured rat dentate granule cells. Neurosci Lett 2004; 356: 25-28, doi: 10.1016/j.neulet.2003.11.012.

4. Chamoun R, Suki D, Gopinath SP, Goodman JC, Robertson C. Role of extracellular glutamate measured by cerebral microdialysis in severe traumatic brain injury. $J$ Neurosurg 2010; 113: 564-570, doi: 10.3171/2009.12.JNS09689.

5. Coyle JT, Puttfarcken P. Oxidative stress, glutamate, and neurodegenerative disorders. Science 1993; 262: 689-695, doi: $10.1126 /$ science.7901908.

6. Wang CY, Kao TC, Lo WH, Yen GC. Glycyrrhizic acid and 18beta-glycyrrhetinic acid modulate lipopolysaccharideinduced inflammatory response by suppression of NFkappaB through PI3K p110delta and p110gamma inhibitions. J Agric Food Chem 2011; 59: 7726-7733, doi: 10.10 21/jf2013265.

7. Birari RB, Gupta S, Mohan CG, Bhutani KK. Antiobesity and lipid lowering effects of Glycyrrhiza chalcones: experimental and computational studies. Phytomedicine 2011; 18: 795801, doi: 10.1016/j.phymed.2011.01.002.

8. Kwon HJ, Kim HH, Ryu YB, Kim JH, Jeong HJ, Lee SW, et al. In vitro anti-rotavirus activity of polyphenol compounds isolated from the roots of Glycyrrhiza uralensis. Bioorg Med Chem 2010; 18: 7668-7674, doi: 10.1016/j.bmc.2010. 07.073.

9. Wu TY, Khor TO, Saw CL, Loh SC, Chen Al, Lim SS, et al. Anti-inflammatory/Anti-oxidative stress activities and differential regulation of Nrf2-mediated genes by non-polar fractions of tea Chrysanthemum zawadskii and licorice Glycyrrhiza uralensis. AAPS J 2011; 13: 1-13, doi: 10.1208/ s12248-010-9239-4.

10. Matsui S, Matsumoto H, Sonoda Y, Ando K, Aizu-Yokota E, Sato $\mathrm{T}$, et al. Glycyrrhizin and related compounds downregulate production of inflammatory chemokines IL-8 and eotaxin 1 in a human lung fibroblast cell line. Int Immunopharmacol 2004; 4: 1633-1644, doi: 10.1016/j. intimp.2004.07.023.

11. Cinatl J, Morgenstern B, Bauer G, Chandra P, Rabenau H, Doerr HW. Glycyrrhizin, an active component of liquorice

\section{Acknowledgments}

This research was supported by the National Science and Technology Support Program of P.R. China (\#2012BAL29B05) and the Major Scientific and Technological Double Ten Project in Jilin Province (\#20130201006ZY). roots, and replication of SARS-associated coronavirus. Lancet 2003; 361: 2045-2046, doi: 10.1016/S01406736(03)13615-X

12. Kao TC, Shyu MH, Yen GC. Neuroprotective effects of glycyrrhizic acid and 18beta-glycyrrhetinic acid in PC12 cells via modulation of the PI3K/Akt pathway. J Agric Food Chem 2009; 57: 754-761, doi: 10.1021/jf802864k.

13. Cherng JM, Lin HJ, Hung MS, Lin YR, Chan MH, Lin JC Inhibition of nuclear factor kappaB is associated with neuroprotective effects of glycyrrhizic acid on glutamateinduced excitotoxicity in primary neurons. Eur J Pharmacol 2006; 547: 10-21, doi: 10.1016/j.ejphar.2006.06.080.

14. Hu Y, Li J, Liu P, Chen X, Guo DH, Li QS, et al. Protection of SH-SY5Y neuronal cells from glutamate-induced apoptosis by 3,6'-disinapoyl sucrose, a bioactive compound isolated from Radix Polygala. J Biomed Biotechnol 2012; 2012: 1-5.

15. Jang JY, Kim HN, Kim YR, Choi YW, Choi YH, Lee JH, et al. Hexane extract from Polygonum multiflorum attenuates glutamate-induced apoptosis in primary cultured cortical neurons. J Ethnopharmacol 2013; 145: 261-268, doi: 10.1016/j.jep.2012.10.061.

16. El-Najjar N, Chatila M, Moukadem H, Vuorela H, Ocker M, Gandesiri M, et al. Reactive oxygen species mediate thymoquinone-induced apoptosis and activate ERK and JNK signaling. Apoptosis 2010; 15: 183-195, doi: 10.1007/ s10495-009-0421-z.

17. Adams JM, Cory S. The Bcl-2 protein family: arbiters of cell survival. Science 1998; 281: 1322-1326, doi: 10.1126/ science.281.5381.1322

18. Lin YL, Wang GJ, Huang CL, Lee YC, Liao WC, Lai WL, et al. Ligusticum chuanxiong as a potential neuroprotectant for preventing serum deprivation-induced apoptosis in rat pheochromocytoma cells: functional roles of mitogenactivated protein kinases. J Ethnopharmacol 2009; 122: 417-423, doi: 10.1016/j.jep.2009.02.011.

19. Lou H, Fan P, Perez RG, Lou H. Neuroprotective effects of linarin through activation of the PI3K/Akt pathway in amyloidbeta-induced neuronal cell death. Bioorg Med Chem 2011; 19: 4021-4027, doi: 10.1016/j.bmc.2011.05.021.

20. Lu S, Lu C, Han Q, Li J, Du Z, Liao L, et al. Adipose-derived mesenchymal stem cells protect PC12 cells from glutamate excitotoxicity-induced apoptosis by upregulation of XIAP through PI3-K/Akt activation. Toxicology 2011; 279: 189195, doi: 10.1016/j.tox.2010.10.011.

21. Jin $Y$, Yan EZ, Fan Y, Guo XL, Zhao YJ, Zong ZH, et al. Neuroprotection by sodium ferulate against glutamateinduced apoptosis is mediated by ERK and PI3 kinase pathways. Acta Pharmacol Sin 2007; 28: 1881-1890, doi: 
10.1111/j.1745-7254.2007.00634.x

22. Mosmann T. Rapid colorimetric assay for cellular growth and survival: application to proliferation and cytotoxicity assays. J Immunol Methods 1983; 65: 55-63, doi: 10.1016/ 0022-1759(83)90303-4.

23. Yang CL, Chik SC, Li JC, Cheung BK, Lau AS. Identification of the bioactive constituent and its mechanisms of action in mediating the anti-inflammatory effects of black cohosh and related Cimicifuga species on human primary blood macrophages. J Med Chem 2009; 52: 6707-6715, doi: 10.1021/ jm9006164.

24. Kim SW, Jin $Y$, Shin JH, Kim ID, Lee HK, Park S, et al. Glycyrrhizic acid affords robust neuroprotection in the postischemic brain via anti-inflammatory effect by inhibiting HMGB1 phosphorylation and secretion. Neurobiol Dis 2012; 46: 147-156, doi: 10.1016/j.nbd.2011.12.056.

25. Lee CS, Kim YJ, Han ES. Glycyrrhizin protection against 3morpholinosydnonime-induced mitochondrial dysfunction and cell death in lung epithelial cells. Life Sci 2007; 80: 1759-1767, doi: 10.1016/j.Ifs.2007.02.003.

26. Sun Q, Wang F, Li W, Li W, Hu YC, Li S, et al. Glycyrrhizic acid confers neuroprotection after subarachnoid hemorrhage via inhibition of high mobility group box-1 protein: a hypothesis for novel therapy of subarachnoid hemorrhage. Med Hypotheses 2013; 81: 681-685, doi: 10.1016/j.mehy. 2013.07.026.

27. Xia Z, Dickens M, Raingeaud J, Davis RJ, Greenberg ME. Opposing effects of ERK and JNK-p38 MAP kinases on apoptosis. Science 1995; 270: 1326-1331, doi: 10.1126/ science.270.5240.1326.

28. Lee CS, Kim YJ, Lee MS, Han ES, Lee SJ. 18betaGlycyrrhetinic acid induces apoptotic cell death in SiHa cells and exhibits a synergistic effect against antibiotic anti-cancer drug toxicity. Life Sci 2008; 83: 481-489, doi: 10.1016/ j.Ifs.2008.07.014.

29. Raisova M, Hossini AM, Eberle J, Riebeling C, Wieder T, Sturm I, et al. The Bax/Bcl-2 ratio determines the susceptibility of human melanoma cells to CD95/Fas-mediated apoptosis. J Invest Dermatol 2001; 117: 333-340, doi: 10.1046/j.0022-202x.2001.01409.x.

30. Zhang L, Zhang S. Modulating Bcl-2 family proteins and caspase-3 in induction of apoptosis by paeoniflorin in human cervical cancer cells. Phytother Res 2011; 25: 1551-1557, doi: 10.1002/ptr.3534.

31. Luo M, Lu Z, Sun H, Yuan K, Zhang Q, Meng S, et al. Nuclear entry of active caspase-3 is facilitated by its p3recognition-based specific cleavage activity. Cell Res 2010; 20: 211-222, doi: 10.1038/cr.2010.9.

32. Boucher MJ, Morisset J, Vachon PH, Reed JC, Laine J, Rivard N. MEK/ERK signaling pathway regulates the expression of $\mathrm{Bcl}-2, \mathrm{Bcl}-\mathrm{X}(\mathrm{L})$, and $\mathrm{Mcl}-1$ and promotes survival of human pancreatic cancer cells. $J$ Cell Biochem 2000; 79: 355-369, doi: 10.1002/1097-4644(20001201) 79:3<355::AID-JCB20>3.0.CO;2-0.

33. Chueh FS, Hsiao YT, Chang SJ, Wu PP, Yang JS, Lin JJ, et al. Glycyrrhizic acid induces apoptosis in WEHI-3 mouse leukemia cells through the caspase- and mitochondriadependent pathways. Oncol Rep 2012; 28: 2069-2076.

34. Khan R, Khan AQ, Lateef A, Rehman MU, Tahir M, Ali F, et al. Glycyrrhizic acid suppresses the development of precancerous lesions via regulating the hyperproliferation, inflammation, angiogenesis and apoptosis in the colon of Wistar rats. PLoS One 2013; 8: e56020, doi: 10.1371/ journal.pone.0056020. 